\title{
Optimal dosage of cefmetazole for intraoperative antimicrobial prophylaxis in patients undergoing surgery for colorectal cancer
}

Atsushi Tomizawa ${ }^{1 *}$, Takatoshi Nakamura², Toshiaki Komatsu', Hiroshi Inano', Rumiko Kondo', Masahiko Watanabe ${ }^{2}$ and Koichiro Atsuda ${ }^{1}$

\begin{abstract}
Background: Few studies have reported the dosage of cefmetazole (CMZ) for intraoperative antimicrobial prophylaxis in patients underwent surgery for colorectal cancer. We therefore examined the optimal intraoperative dosage of CMZ according to pharmacokinetic/pharmacodynamic (PK/PD) theory in patients who undergoing surgery for colorectal cancer.

Methods: The study group comprised 23 patients with colorectal cancer who underwent surgery, using CMZ as antimicrobial treatment to prevent postoperative infection. CMZ was administered intravenously within 60 min before surgery. PK/PD analysis was performed by population pharmacokinetic analysis and Monte-Carlo simulation.

Results: The final population pharmacokinetic parameters of $C M Z$ were as follows: $\mathrm{CL}_{\mathrm{CMZ}}=0.0704 \times$ creatinine clearance $(\mathrm{Ccr})$ and $\mathrm{Vd}_{\mathrm{CMZ}}=0.163 \times$ body weight (Bw). In patients with a $\mathrm{Ccr}$ of $\geq 90$ to $<130 \mathrm{~mL} / \mathrm{min}$, the probability of achieving concentrations exceeding MIC was 52.9 to $82.2 \%$ at $2 \mathrm{~h}$ after the initial dose and less than $20 \%$ at $3 \mathrm{~h}$ after the initial dose.
\end{abstract}

Conclusions: Additional doses of CMZ should be given every $2 \mathrm{~h}$ in patients with a Ccr of $\geq 90$ to $<130 \mathrm{~mL} / \mathrm{min}$, every $3 \mathrm{~h}$ in those with a Ccr of $\geq 50$ to $<90 \mathrm{~mL} / \mathrm{min}$, and every 4 to $5 \mathrm{~h}$ in those with a Ccr of $\geq 10$ to $<50 \mathrm{~mL} / \mathrm{min}$.

Keywords: Cefmetazole, Colorectal surgery, Antimicrobial prophylaxis, Population pharmacokinetics

\section{Background}

Cefmetazole (CMZ) is a cephamycin's antibiotics developed in Japan that has high antibacterial activity against gram-negative and anaerobic bacteria. It is widely used for antimicrobial prophylaxis (AMP) in patients undergoing lower gastrointestinal surgery [1].

Treatment schedules for AMP have been based on the Centers for Disease Control and Prevention guidelines [2], the recommendations of the Surgical Infection Prevention Guideline Writers Workgroup meeting [3], and recent collaborative guidelines issued by the American Society of Health-System Pharmacists, the Infectious
Diseases Society of America, the Surgical Infection Society, and the Society for Healthcare Epidemiology of America [4]. A general consensus has also been reached in Japan. However, very few studies have evaluated the pharmacokinetics of CMZ during surgery for colorectal cancer and reported the optimal intraoperative treatment schedule for CMZ, including the timing of additional doses.

We studied the pharmacokinetics of CMZ during surgery in patients with colorectal cancer to determine the optimal dosage of CMZ on the basis of pharmacokinetics and pharmacodynamics.

\footnotetext{
* Correspondence: tomy@kitasato-u.ac.jp

'Department of Pharmacy, Kitasato University Hospital, 1-15-1 Kitasato,

Minami-ku, Sagamihara, Kanagawa 252-0374, Japan

Full list of author information is available at the end of the article
} 


\section{Methods}

\section{Data source}

The study group comprised 23 patients who underwent surgery for colorectal cancer and received CMZ for AMP between November 2008 and December 2010. Patients who underwent emergency surgery, those with ileus, and those who were receiving dialysis were excluded.

As for the treatment schedule, $1 \mathrm{~g}$ of CMZ was intravenously administered over the course of 5 to $10 \mathrm{~min}$ after the induction of anesthesia and within $60 \mathrm{~min}$ before the surgical incision. Subsequently, $1 \mathrm{~g}$ of CMZ was additionally given every $3 \mathrm{~h}$. In principle, blood samples were collected at the start of surgery, on completion of the anastomosis, immediately before additional doses of AMP, and after abdominal closure.

\section{Assay of cefmetazole concentrations}

Serum CMZ concentrations were measured by highperformance liquid chromatography (HPLC). After the completion of surgery, blood samples were centrifuged at $3000 \mathrm{rpm}$ for $10 \mathrm{~min}$, and the serum supernatant was preserved by freezing at $-80{ }^{\circ} \mathrm{C}$ until assay. At the time of assay, $200 \mu \mathrm{L}$ of serum was combined with $90 \mu \mathrm{L}$ of a deproteinizing agent $\left(1 \mathrm{M} \mathrm{HClO}_{4}\right)$, and the mixture was centrifuged at $1000 \mathrm{rpm}$ and $4{ }^{\circ} \mathrm{C}$ for $5 \mathrm{~min}$. The obtained supernatant was filtered through a $0.45-\mu \mathrm{m}$ syringe filter, and $50 \mu \mathrm{L}$ of the filtrate was injected into a chromatograph. The HPLC column temperature was $25{ }^{\circ} \mathrm{C}$, with an ultraviolet absorption wavelength of $256 \mathrm{~nm}$. The mobile phase was prepared by combining $800 \mathrm{~mL}$ of $50 \mathrm{mM}$ phosphate buffer $(\mathrm{pH} 4.5)$ with $200 \mathrm{~mL}$ of acetonitrile. The detection limit was $0.5 \mu \mathrm{g} / \mathrm{mL}$.

\section{Pharmacokinetics model}

Population pharmacokinetic analysis of CMZ was performed with the use of a nonlinear mixed effect model (NONMEM) program (version VI, level 1.0). For the pharmacokinetic model, we used predictions for population pharmacokinetics (PREDPP) subroutines with a linear one-compartment model (ADVAN 1 and TRANS 2) to estimate the pharmacokinetic parameters of the volume of distribution $\left(\mathrm{Vd}_{\mathrm{CMZ}}\right)$ and clearance $\left(\mathrm{CL}_{\mathrm{CMZ}}\right)$.

The inter-individual variability of the pharmacokinetic parameters was assessed using an exponential error model according to the following eq (1):

$$
P_{j}=P \times \exp \left(\eta_{j}\right)
$$

Where $P_{j}$ is parameter value of the $\mathbf{j}$-th subject, $P$ is the estimated population mean, and $\eta_{i}$ is a random variable with a mean of 0 and a variance of $\omega^{2}$.
Table 1 Demographic characteristics of the patients

\begin{tabular}{llll}
\hline Parameter & Numbers & Mean \pm SD & Range \\
\hline Gender (male/female) & $18 / 5$ & & \\
Cancer (colon / rectum) & $14 / 9$ & & \\
Stage (I/I/III//V) & $10 / 6 / 6 / 1$ & & \\
Procedure (lap ${ }^{\mathrm{a}} /$ open) & $13 / 10$ & & \\
Age (years) & & $69 \pm 10$ & $41-84$ \\
Body weight $(\mathrm{kg})$ & $63.7 \pm 9.9$ & $47.5-89.0$ \\
Body mass index $\left(\mathrm{kg} / \mathrm{m}^{2}\right)$ & & $24.1 \pm 4.1$ & $19.0-34.3$ \\
Serum creatinine $(\mathrm{mg} / \mathrm{dL})$ & & $0.84 \pm 0.17$ & $0.57-1.3$ \\
Creatinine clearance $(\mathrm{mL} / \mathrm{min})$ & & $73.9 \pm 21.7$ & $47.2-126.3$ \\
Serum albumin $(\mathrm{g} / \mathrm{dL})$ & & $3.8 \pm 0.4$ & $3.3-4.6$ \\
Operation time $(\mathrm{min})$ & & $238 \pm 73$ & $140-430$ \\
\hline
\end{tabular}

a lap laparoendoscopic procedure

The intra-individual variability of the parameters was assessed using a proportional error model according to the following eq (2):

$$
\mathrm{C}_{i j}=\mathrm{C}_{\text {pred }, i j} \times\left(1+\varepsilon_{i j}\right)
$$

Where $\mathrm{C}_{i j}$ and $\mathrm{C}_{\text {predij }}$ denotes observed and predicted concentrations for the $\mathrm{j}$-th subject at $i$-th time, and $\varepsilon$ is a random intra-individual error which is normally distributed with mean 0 and variance $\sigma^{2}$.

\section{Covariate analysis}

The covariates of patients were performed for their influence on CMZ pharmacokinetic parameters as followed; age (Age), gender (Gender), body weight (Bw),

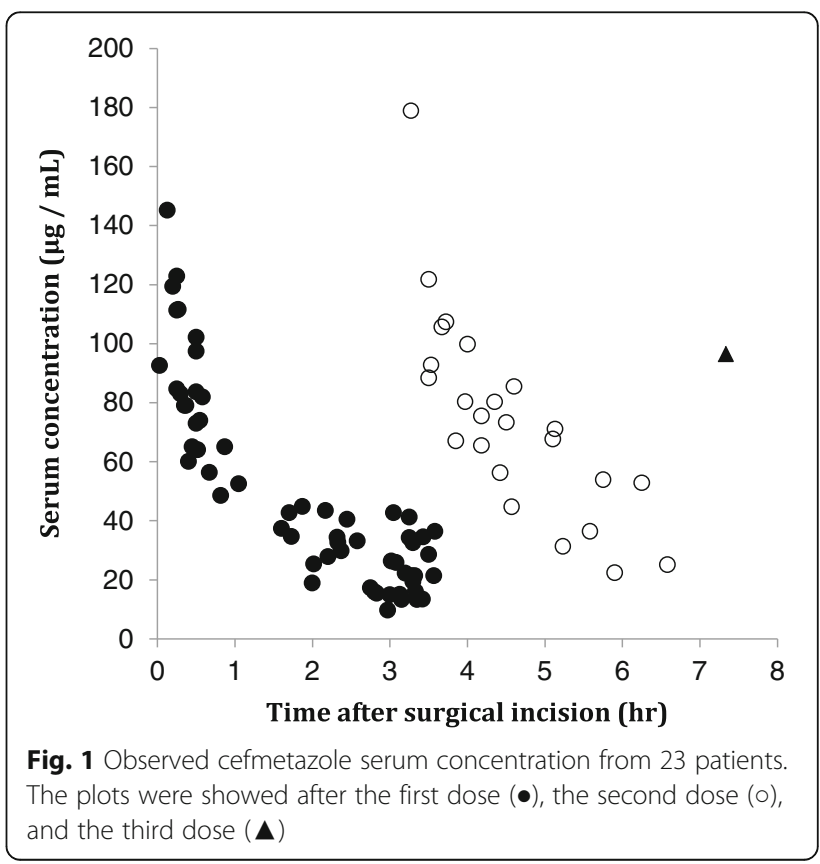


Table 2 Hypothesis testing for fixed efects model on cefmetazole parameters

\begin{tabular}{|c|c|c|c|c|}
\hline Parameter & Fixed effects model & OBJ & - 2 I.I.d. & $p$-value \\
\hline \multirow[t]{9}{*}{$\mathrm{CL}$} & $\theta 1$ & 491.305 & & \\
\hline & $\theta 1+\theta 2 \times C c r$ & 476.461 & -14.844 & 0.001 \\
\hline & $\theta 1+\theta 2 \times 1 / \operatorname{Scr}$ & 486.958 & -4.347 & N.S. \\
\hline & $\theta 1 \times \theta 2^{\text {Gender }}($ Gender: male $=1$, female $=0)$ & 486.934 & -4.371 & N.S. \\
\hline & $\theta 1 ;$ Age $\geqq 65, \theta 2 ;$ Age $<65$ & 491.291 & -0.014 & N.S. \\
\hline & $\theta 1 ; A l b \geqq 3.8, \theta 2 ; A l b<3.8$ & 491.305 & 0 & N.S. \\
\hline & $\theta 1+\theta 2 \times(1+(4-$ stage $))$ & 490.054 & -1.251 & N.S. \\
\hline & $\theta 1 \times \theta 2^{\text {Procedure }}$ & 491.074 & -0.231 & N.S. \\
\hline & $\theta 1+\theta 2 \times B W$ & 489.316 & -1.989 & N.S. \\
\hline \multirow[t]{3}{*}{$\mathrm{Vd}$} & $\theta 1 \times \theta 2^{\text {Gender }}($ Gender $:$ male $=1$, female $=0$ ) & 491.295 & 0.010 & N.S. \\
\hline & $\theta 1 ;$ Age $\geqq 65, \theta 4 ;$ Age $<65$ & 490.189 & 1.116 & N.S. \\
\hline & $\theta 1+\theta 2 \times B W$ & 473.811 & 17.494 & 0.001 \\
\hline
\end{tabular}

-2 I.I.d. : -2 log likelihood difference

N.S. Not significant

clinical pathological stage (Stage), serum creatinine (Scr), creatinine clearance (Ccr), serum albumin (Alb), and operative procedure (Procedure). Operative procedures were divided into open surgery and laparoscopic surgery. Ccr was calculated using the Cockcroft-Gault equation.

The influence of continuous covariates on the pharmacokinetic parameter was modeled according to the following eqs $(3,4)$ :

$$
\begin{aligned}
& \mathrm{P}=\theta p+\theta \mathrm{c} \times(\text { covariance }) \\
& \mathrm{P}=\theta p \times \theta \mathrm{c}^{(\text {covariance })}
\end{aligned}
$$

The significance of the influence of covariates was evaluated by the change of -2 log likelihood (the minimum value of the objective function: $\mathrm{OBJ}$ ).

Statistical significance was indicated by a $\mathrm{p}$ value of $<0.01$. Only covariates providing a significant change in the OBJ were included in the full model and were then tested in a backward deletion step, with statistical significance indicated by a $\mathrm{p}$ value of $<0.001$. The ability of the final population pharmacokinetic model to describe adequately the observed data was evaluated using visual predictive values.

\section{Model evaluation}

Actual serum CMZ concentrations in individual patients $(\mathrm{Cp})$, predicted concentrations based on population parameters (PRED), and estimated individual predicted concentration calculated by Bayesian fitting (IPRED) were plotted to derive regression equations. Weighted residual values for $\mathrm{Cp}$ and PRED were plotted to evaluate the accuracy of serum concentrations estimated by the final model.
Parameter precision and model stability were estimated for the final model by the bootstrap method [5].200 bootstrap samples were reconstructed, and the final model was determined by the 200 bootstrap samples repeatedly tested. The mean and standard error (S.E.) for each estimated parameters calculated normally were compared with those obtained from the original data set.

\section{Evaluation of optimal dosage}

A Monte-Carlo simulation [6] was performed 1000 times with the estimated and dispersion values of the population pharmacokinetic parameters, using Microsoft Excel $2010^{\circ}$. Estimated serum CMZ concentrations were calculated after 2, 3, 4, 5, and $6 \mathrm{~h}$. On the basis of the minimum inhibitory concentration (MIC) distribution of Bacteroides fragilis, the probability of achieving serum $\mathrm{CMZ}$ concentrations above the $\mathrm{MIC}_{80}$ : MIC attainment rate, was calculated. As for the MIC distribution of Bacteroides fragilis for $\mathrm{CMZ}$, a Japanese surveillance report

Table 3 Final pharmacokinetic parameter estimates for cefmetazole in patients undergoing colorectal surgery

\begin{tabular}{ll}
\hline Pharmacokinetic Parameters & \\
$\mathrm{CLCMZ}=\theta 1 \times \mathrm{Ccr}$ & $(\mathrm{L} / \mathrm{h})$ \\
$\mathrm{VdCMZ}=\theta 2 \times \mathrm{BW}$ & $(\mathrm{L})$ \\
Estimate & \\
$\theta 1$ & 0.0704 \\
$\theta 2$ & 0.163 \\
Variability & \\
$\omega \mathrm{CL}(\%)$ & 21.0 \\
$\omega \mathrm{Vd}(\%)$ & 8.4 \\
$\sigma(\%)$ & 13.5 \\
\hline
\end{tabular}



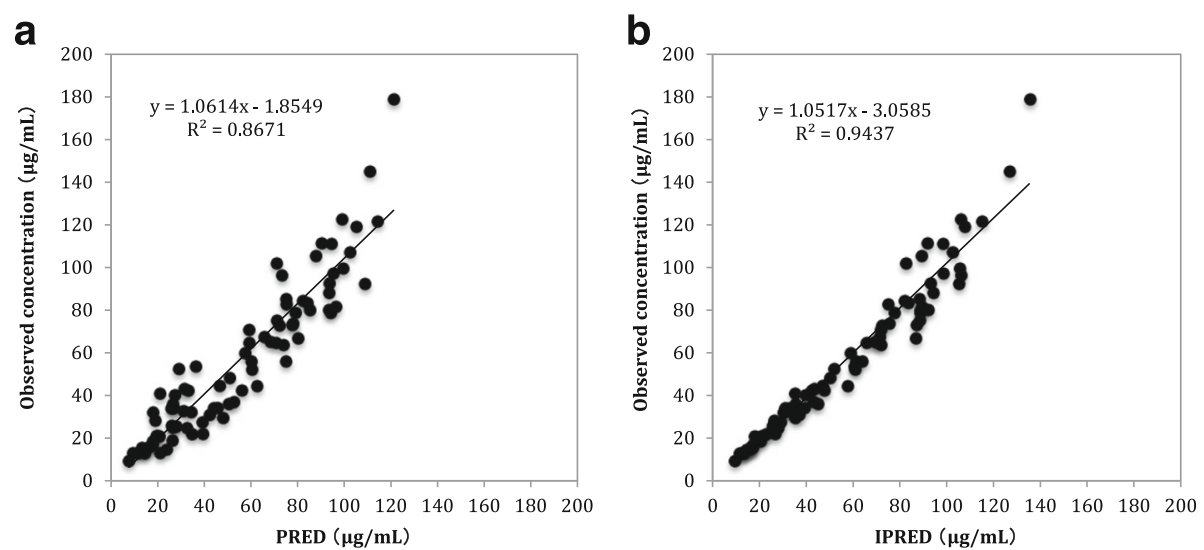

Fig. 2 a Relationship between observed concentration and predicted concentration based on population mean parameters using the Final model (PRED). b Relationship between observed concentration and individual predicted concentration after Bayesian fitting (IPRED)

of the antimicrobial susceptibility of clinical isolates of anaerobic bacteria in 2004 was used.

\section{Results}

Table 1 shows the demographic characteristics of the patients. Serum concentrations were measured at a total of 86 points. The time course of serum CMZ concentrations is shown in Fig. 1. Ccr was a covariate that significantly influenced $\mathrm{CL}_{\mathrm{CMZ}}$, and $\mathrm{Bw}$ was a covariate that significantly influenced $\mathrm{Vd}_{\mathrm{CMZ}}$ (Table 2). These factors were integrated into the full model, which was compared with a reduced model. Consequently, the final CMZ population pharmacokinetic estimates were $\mathrm{CL}_{\mathrm{CMZ}}=$ $0.0704 \times \mathrm{Ccr}$ and $\mathrm{Vd}_{\mathrm{CMZ}}=0.163 \times \mathrm{Bw}$. The calculated interindividual variability $(\mathrm{CV} \%)$ was $21.0 \%$ for $\mathrm{CL}_{\mathrm{CMZ}}$ and $8.4 \%$ for $\mathrm{Vd}_{\mathrm{CMZ}}$, and the residual variability was $13.5 \%$ (Table 3).

On regression analysis of $\mathrm{Cp}$ and PRED, a correlation coefficient of $\mathrm{r}^{2}=0.8671$ was obtained (Fig. 2a). On regression analysis of Cp and IPRED, a correlation coefficient of $r^{2}=0.9437$ was obtained (Fig. 2b). Weighted residuals (WRES) estimated on the basis of $\mathrm{Cp}$ and PRED were almost uniformly distributed within a range of about \pm 3 when WRES $=0$ (Fig. 3). The results of bootstrap validation of the estimated pharmacokinetic parameters are shown in Table 4 . The convergence rate was $100 \%(200 / 200)$.

Table 5 shows the probability of attaining predicted serum concentrations above the MIC of Bacteroides fragilis : MIC target attainment rate, according to Ccr and $\mathrm{Bw}$, calculated on Monte Carlo simulation of the population pharmacokinetic parameters. The MIC target attainment rate $3 \mathrm{~h}$ after the initial dose of CMZ was 3.39 to $15.6 \%$ in patients with a Ccr of $\geq 90$ to $<130 \mathrm{~mL} / \mathrm{min}$, 57.9 to $81.5 \%$ in those with a Ccr of $\geq 50$ to $<90 \mathrm{~mL} / \mathrm{min}$, and 96.0 to $96.7 \%$ in those with a Ccr of $\geq 10$ to $<50 \mathrm{~mL} /$ min. The MIC target attainment rate at $2 \mathrm{~h}$ after the initial dose of CMZ was 52.9 to $82.2 \%$ in patients with a Ccr of $\geq 90$ to $<130 \mathrm{~mL} / \mathrm{min}$ and $90 \%$ or higher in patients with a Ccr of 50 to $<90 \mathrm{~mL} / \mathrm{min}$, irrespective of Bw. In patients with a Ccr of $\geq 10$ to $<50 \mathrm{~mL} / \mathrm{min}$, the MIC target attainment rate $5 \mathrm{~h}$ after the initial dose of CMZ was 81.2 to $90.6 \%$.

\section{Discussion}

Outside of Japan, cefoxitin and cefotetan are used as perioperative antimicrobial prophylaxis in patients who undergoing surgery for colorectal cancer [2-4]. Because these drugs cannot be used in Japan, however, CMZ, which is also a cephamycin's antibiotics, is widely employed. Few studies have examined the optimal dosage of CMZ in patients under surgery, including the

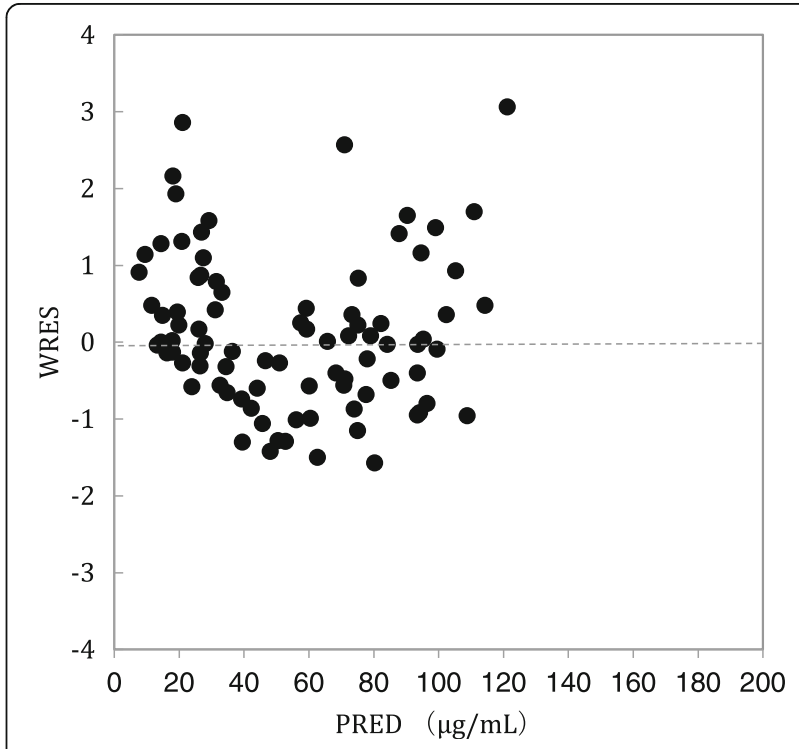

Fig. 3 Weighted residuals between observed concentration and PRED (WRES) versus PRED 
Table 4 Bootstrap validation of the estimated pharmacokinetic parameters

\begin{tabular}{lccc}
\hline Parameter & Final model $^{\mathrm{a}}($ mean \pm S.E. $)$ & Bootstrap $^{\mathrm{b}}(\mathrm{mean} \pm$ S.E. $)$ & Difference $^{c}$ \\
\hline$\theta 1(\mathrm{CL})$ & $0.0704 \pm 0.0029$ & $0.0703 \pm 0.0029$ & $-0.001 \%$ \\
$\theta 2(\mathrm{Vd})$ & $0.163 \pm 0.0054$ & $0.164 \pm 0.0057$ & $0.6 \%$ \\
$\omega \mathrm{CL}$ & $0.210 \pm 0.0137$ & $0.202 \pm 0.0350$ & $-3.8 \%$ \\
$\omega \mathrm{Vd}$ & $0.084 \pm 0.0053$ & $0.070 \pm 0.0377$ & $-16.7 \%$ \\
$\sigma$ & $0.135 \pm 0.0045$ & $0.133 \pm 0.0165$ & $-1.5 \%$ \\
\hline
\end{tabular}

${ }^{\mathrm{a}}$ Obtained from the original data set

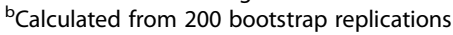

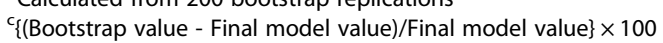

intraoperative administration of additional doses. We believe that it is extremely important to assess the optimal dosage of CMZ on the basis of PK/PD theory.

The $\mathrm{CL}_{\mathrm{CMZ}}$ obtained on population pharmacokinetic analysis was dependent on $\mathrm{Ccr}$, and $\mathrm{Vd}_{\mathrm{CMZ}}$ was dependent on Bw. These findings were considered reasonable because more than $85 \%$ of CMZ is excreted as the unchanged compound in the urine, and excretion is mainly renal. A $\mathrm{CL}_{\mathrm{CMZ}}$ of $7.04 \mathrm{~L} / \mathrm{h}(\mathrm{Ccr}: 100 \mathrm{~mL} / \mathrm{min})$ and a $\mathrm{Vd}_{\mathrm{CMZ}}$ of $10.4 \pm 1.6 \mathrm{~L}$ (Bw : 47.5 to $89.0 \mathrm{~kg}$ ) were generally consistent with the results of Borin et al. (CL : $6.96 \mathrm{~L} / \mathrm{h}, \mathrm{Vd}: 11.9 \pm 4.2 \mathrm{~L}$ ) [7] and Wong-Beringer et al. (Vd : 0.14 to $0.28 \mathrm{~L} / \mathrm{kg}$ ) [8].

Finally, models were prepared for estimating $\mathrm{CL}_{\mathrm{CMZ}}$ on the basis of Ccr, and $\mathrm{Vd}_{\mathrm{CMZ}}$ on the basis of $\mathrm{Bw}$. These data can be obtained from serum chemical analysis before surgery, thus resulting in a clinically appropriate and practical model.

On diagnosis of the final model, regression analysis showed that a high correlation coefficient was obtained between observed serum CMZ concentrations and predicted CMZ concentrations based on population mean parameters, with a high regression coefficient, suggesting that predicted concentrations based on population mean parameters were good. On bootstrap validation, the mean bootstrap values approximated the final model

Table 5 The target attainment rate above MIC80 of Bacteroides fragilis calculated on Monte Carlo simulation

\begin{tabular}{|c|c|c|c|c|c|c|}
\hline \multirow[b]{2}{*}{$\mathrm{Bw}(\mathrm{kg})$} & \multirow[b]{2}{*}{$\operatorname{Ccr}(\mathrm{mL} / \mathrm{min})$} & \multirow[b]{2}{*}{$2 \mathrm{~h}$} & \multicolumn{4}{|c|}{ The target attainment rate } \\
\hline & & & $3 \mathrm{~h}$ & $4 \mathrm{~h}$ & $5 \mathrm{~h}$ & $6 \mathrm{~h}$ \\
\hline & $\geqq 90$ to $<130$ & $52.87 \%$ & $3.39 \%$ & $0.00 \%$ & $0.00 \%$ & $0.00 \%$ \\
\hline \multirow[t]{3}{*}{$\geqq 40$ to 50} & $\geqq 50$ to $<90$ & $91.24 \%$ & $57.89 \%$ & $19.42 \%$ & $3.45 \%$ & $0.37 \%$ \\
\hline & $\geqq 10$ to $<50$ & $98.66 \%$ & $96.67 \%$ & $92.96 \%$ & $81.20 \%$ & $66.08 \%$ \\
\hline & $\geqq 90$ to $<130$ & $72.44 \%$ & $8.56 \%$ & $0.14 \%$ & $0.00 \%$ & $0.00 \%$ \\
\hline \multirow[t]{3}{*}{$\geqq 50$ to 60} & $\geqq 50$ to $<90$ & $92.17 \%$ & $72.40 \%$ & $33.66 \%$ & $8.28 \%$ & $2.33 \%$ \\
\hline & $\geqq 10$ to $<50$ & $98.19 \%$ & $96.71 \%$ & $93.43 \%$ & $88.53 \%$ & $74.18 \%$ \\
\hline & $\geqq 90$ to $<130$ & $82.16 \%$ & $15.57 \%$ & $1.58 \%$ & $0.00 \%$ & $0.00 \%$ \\
\hline \multirow[t]{2}{*}{$\geqq 60$ to 70} & $\geqq 50$ to $<90$ & $92.69 \%$ & $81.51 \%$ & $44.25 \%$ & $15.74 \%$ & $4.78 \%$ \\
\hline & $\geqq 10$ to $<50$ & $97.27 \%$ & $96.06 \%$ & $93.16 \%$ & $90.56 \%$ & $79.45 \%$ \\
\hline
\end{tabular}

values. The robustness was $100 \%(200 / 200)$ on normal completion of calculation, thus demonstrating the internal validity of the population parameters.

When the optimal treatment schedule for CMZ was assessed using the obtained population pharmacokinetic parameters, the MIC attainment rate at $2 \mathrm{~h}$ after initial treatment was 52.9 to $82.2 \%$ in patients with a Ccr of $\geq 90$ to $<130 \mathrm{~mL} / \mathrm{min}$ irrespective of Bw. In contrast, the MIC attainment rate was less than $20 \%$ at $3 \mathrm{~h}$ after initial treatment. This finding suggested that additional doses should be given every $2 \mathrm{~h}$ after the initial dose in patients with a $\mathrm{Ccr}$ of $\geq 90$ to $<130 \mathrm{~mL} / \mathrm{min}$. Collaborative guidelines for AMP published in 2013 [4] recommended that additional doses of cefoxitin, a drug belonging to the same category as CMZ, should be given every $2 \mathrm{~h}$ after the initial dose in patients with normal renal function. Therefore, the timing for additional doses of CMZ in patients with a Ccr of $\geq 90$ to $<130 \mathrm{~mL} / \mathrm{min}$ is considered consistent with the recommendations of current guidelines $[3,4]$.

However, the essential goal of AMP is to decrease bacterial counts to a level that does not cause infection, given the susceptibility of the individual patient to infection. Therefore, treatment schedules should be adjusted according to the $\mathrm{Bw}$ and renal function of individual patients, rather than indiscriminately giving additional treatment to all patients.

Our results suggest that additional dose of $\mathrm{CMZ}$ should be given every $2 \mathrm{~h}$ in patients with a Ccr of $\geq 90$ to $<130 \mathrm{~mL} / \mathrm{min}$, every $3 \mathrm{~h}$ to those with a Ccr of $\geq 50$ to $<90 \mathrm{~mL} / \mathrm{min}$, and every 4 to $5 \mathrm{~h}$ in those with a Ccr of $\geq 10$ to $<50 \mathrm{~mL} / \mathrm{min}$. Our limitation was the low number of renal failure $(\mathrm{Ccr}$ of $<50 \mathrm{~mL} / \mathrm{min})$ patient $(n=1)$. Therefore our recommended dosage should be adjusted to each individual clinical situation and care must be taken with patients to $\mathrm{Ccr}$ of $<50 \mathrm{~mL} / \mathrm{min}$.

Further studies of larger number of patients are required to confirm whether our results are consistent with external data and to assess the relation between the MIC attainment rate and the risk of surgical site infection. 


\section{Conclusions}

We studied to determine the optimal dosage of CMZ during surgery in patients with colorectal cancer.

Our results suggest that additional dose of $\mathrm{CMZ}$ should be given every $2 \mathrm{~h}$ in patients with a Ccr of $\geq 90$ to $<130 \mathrm{~mL} / \mathrm{min}$, every $3 \mathrm{~h}$ to those with a Ccr of $\geq 50$ to $<90 \mathrm{~mL} / \mathrm{min}$, and every 4 to $5 \mathrm{~h}$ in those with a Ccr of $\geq 10$ to $<50 \mathrm{~mL} / \mathrm{min}$.

\section{Abbreviations}

AMP: Antimicrobial prophylaxis; Bw: Body weight; Ccr: Creatinine clearance; CL: Clearance; CMZ: Cefmetazole; HPLC: High-performance liquid chromatography; MIC: Minimum inhibitory concentration; OBJ: Objective function; PK/PD: Pharmacokinetic/pharmacodynamic; Vd: Volume of distribution

\section{Acknowlegements}

We are indebted to Professor Kazuo Yago, Dr. Hirotsugu Okamoto, Ms. Saki Nara for their guidance and cooperation in this study.

\section{Funding}

There are no funding sources for this report.

\section{Availability of data and materials}

Not applicable.

\section{Authors' contributions}

AT wrote the manuscript. AT, TN and TK analyzed and interpreted the patient data regarding for colorectal cancer and pharmacokinetic/ pharmacodynamic theory. HI measured cefmetazole concentrations. All authors read and approved the final manuscript.

\section{Competing interests}

The authors declare that they have no competing interests.

\section{Consent for publication}

Not applicable.

\section{Ethics approval and consent to participate}

This study was approved by the Ethics Committee of Kitasato University Hospital (B10-59: approved on July 24, 2010).

\section{Author details}

'Department of Pharmacy, Kitasato University Hospital, 1-15-1 Kitasato, Minami-ku, Sagamihara, Kanagawa 252-0374, Japan. ²Department of Surgery, Kitasato University School of Medicine, 1-15-1 Kitasato, Minami-ku,

Sagamihara, Kanagawa 252-0374, Japan.

Received: 23 October 2016 Accepted: 21 December 2016

Published online: 07 January 2017

\section{References}

1. Kobayashi M, Takesue Y, Kitagawa Y, Kusunoki M, Sumiyama Y. Antimicrobial prophylaxis and Colon Preparation for Colorectal Surgery: Results of a Questionnaire Survey of 721 Certified Institutions in Japan. Surg Today. 2011;41:1363-9.

2. Mangram AJ, Horan TC, Pearson ML, Pearson MR, Silver LC, Javis WR, et al. Guideline for Prevention of Surgical Site Infection, 1999. Centers for Disease Control and Prevention (CDC) Hospital Infection Control Practices Advisory Committee. Am J Infect Control. 1999:27(2):97-134.

3. Bratzler DW, Houck PM. Antimicrobial prophylaxis for surgery: an advisory statement from the National Surgical Infection Prevention Project. Clin Infect Dis. 2004:38:1706-15.

4. Bratzler DW, Dellinger EP, Olsen KM, Perl TM, Auwaerter PG, Bolon MK, et al. Clinical practice guidelines for antimicrobial prophylaxis in surgery. Am J Health-Syst Pharm. 2013;70:195-283.

5. Ette El. Stability and performance of a population pharmacokinetic model. J Clin Pharmacol. 1997;37(6):486-95.
6. Sheppard CW. Computer simulation of stochastic processes through model - sampling (Monte Carlo) techniques. FEBS Lett. 1969; 2(Supplement1):S14-21.

7. Borin MT, Peters GR, Smith TC. Pharmacokinetics and dose proportionality of cefmetazole in healthy young and elderly volunteers. Antimicrob Agents Chemother. 1990;34(10):1944-8.

8. Wong-Beringer A, Corelli RL, Schrock TR, Guglielmo BJ. Influence of timing of antibiotic administration on tissue concentrations during. Am J Surg. 1995:169(4):379-81.
Submit your next manuscript to BioMed Central and we will help you at every step:

- We accept pre-submission inquiries

- Our selector tool helps you to find the most relevant journal

- We provide round the clock customer support

- Convenient online submission

- Thorough peer review

- Inclusion in PubMed and all major indexing services

- Maximum visibility for your research

Submit your manuscript at www.biomedcentral.com/submit 